\title{
LIQUID CHROMATOGRAPHY TANDEM-MASS SPECTROMETRY METHOD DEVELOPMENT AND VALIDATION FOR SIMULTANEOUS ANALYSIS OF PARACETAMOL, GUAIFENESIN, PHENYLEPHRINE HYDROCHLORIDE, CHLORPHENIRAMINE MALEATE, AND AMBROXOL HYDROCHLORIDE IN BULK AND IN TABLET DOSAGE FORM
}

\author{
RANI S POTAWALE ${ }^{1}$, RITU M GILHOTRA ${ }^{1}$, SATISH Y GABHE ${ }^{2 *}$ \\ ${ }^{1}$ Department of research, Suresh Gyan Vihar University, Jagatpura, Jaipur - 302 025, Rajasthan, India. ${ }^{2}$ Department of Pharmaceutical \\ Chemistry, Poona College of Pharmacy, Bharati Vidyapeeth Deemed University (BVDU), Pune - 411038, Maharashtra, India. \\ Email: satishgabhe@gmail.com
}

Received: 24 February 2018, Revised and Accepted: 17 April 2018

ABSTRACT

Objective: The objective is to study liquid chromatography tandem-mass spectrometry (LC/MS/MS) method for simultaneous quantification of paracetamol (PCM), guaifenesin (GUA), phenylephrine hydrochloride (PE), chlorpheniramine maleate (CPM), and ambroxol hydrochloride (AMB) in tablet dosage form developed and validated as per the International Conference on Harmonization Q2 (R1) guideline.

Methods: The chromatograms were developed using a gradient mobile phase of WATER:methanol. Flow rate used was to $0.3 \mathrm{ml} / \mathrm{min}$. Quantitation was performed using multiple reaction monitoring (MRM) mode to study parent to product ion transition, for paracetamol. (m/z 152.0 $\geq 110.0$ ), guaifenesin (m/z $199.0 \geq 163.0)$, phenylephrine hydrochloride (m/z 168.0 2150.0$)$, chlorpheniramine maleate $(\mathrm{m} / \mathrm{z} 275.0 \geq 230.0)$ and ambroxol hydrochloride $(\mathrm{m} / \mathrm{z} 379.0 \geq 263.8)$.

Results: The retention times were found to be 1.76, 1.81, 1.90, 2.10, and 2.33 min for PCM, GUA, PE, CPM, and AMB, respectively. The linearity of the method was found to be in the concentration range of $10-200 \mathrm{ng} / \mathrm{ml}$ for PCM, GUA, PE, CPM, and AMB. Percentage relative standard deviation values for repeatability and intermediate precision studies were below $2 \%$.

Conclusion: Developed method was found to be robust, precise, accurate, rapid and can be used to analyze fixed-dose tablet formulation used in the study.

Keywords: Liquid chromatography tandem-mass spectrometry, Method development, validation, International Conference on Harmonization Q2 (R1).

(c) 2018 The Authors. Published by Innovare Academic Sciences Pvt Ltd. This is an open access article under the CC BY license (http://creativecommons. org/licenses/by/4. 0/) DOI: http://dx.doi.org/10.22159/ajpcr.2018.v11i7.25463

\section{INTRODUCTION}

Paracetamol (PCM) [1,2], an analgesic and antipyretic agent (Fig. 1), is 4-hydroxyacetanilide. Literature survey revealed that spectrophotometric [3], high-performance thin-layer chromatography (HPTLC) [4-6], and HPLC [7-11] methods have been reported for PCM individually or in combination with other drug/s.

Chemically, guaifenesin (GUA) [12,13] an antipruritic, anti-allergic, histamine $\mathrm{H}_{1}$ antagonist (Fig. 2) is 3-(2-methoxyphenoxy) propan-1, 2-diol. Literature survey revealed that spectrophotometric [14-17], HPTLC [18], and HPLC [19-24] analytical methods have been reported for GUA individually or in combination with other drug/s.

Phenylephrine hydrochloride (PE) [25,26], a sympathomimetic agent (Fig. 3), is (R)-1-(3-hydroxyphenyl)-2-methylamino ethanol hydrochloride. Literature survey revealed that spectrophotometric [27], HPTLC [28], and HPLC [29-33] techniques have been reported for PE individually or in combination with other drug/s.

Chlorpheniramine maleate (CPM) [34,35], an antihistaminic and antiallergics (Fig. 4), is (S)-3-(4-chlorophenyl)- $N, N$-dimethyl-3-(-3 pyridin-2-yl) propan-1-amine maleate. Spectrophotometric [36,37], HPTLC [38], and HPLC [39-44] analytical methods have been reported for CPM individually or in combination with other drug/s.

Ambroxol hydrochloride (AMB) [45], a mucolytic agent (Fig. 5), is trans-4-[(2-amino-3, 5-dibromo benzyl) amino] cyclohexanol hydrochloride. Literature survey showed spectrophotometric $[46,47]$,
HPTLC [48,49], and HPLC [50-54] methods of analysis for AMB individually or in combination with other drug/s.

A detailed survey of analytical literature for the estimation of these drugs revealed that there was no liquid chromatography tandemmass spectrometry (LC/MS/MS) method available for simultaneous estimation of these drugs in combined tablet form. Hence, the present research study was undertaken.

\section{METHODS}

Pharmaceutical grade PCM, CPM, AMB, GUA, and PE were received as gift sample from Centaur Pharmaceuticals Ltd. and Emcure Pharmaceuticals Ltd., Pune, India. Drug formulation used in the study was Solvin Cold (Ipca Laboratories Ltd., Mumbai, India) containing PCM $500 \mathrm{mg}$, GUA $100 \mathrm{mg}$, AMB $30 \mathrm{mg}$, PE $10 \mathrm{mg}$, and CPM $2 \mathrm{mg}$, purchased from the local market. HPLC grade chemicals and reagents were used for LC/MS/MS analyses.

Instrumentation and chromatographic conditions

The LC/MS/MS system consisted of a HPLC system-1260 infinity with auto-injector $(20 \mu \mathrm{l})$. Agilent MS 6460 triple quadruple MS was used. The software used was Agilent mass hunter workstation data acquisition with version 1.18.03. The column used was Poroshell 120 EC - C18 $(4.6 \times 50 \mathrm{~mm} 2.7 \mu \mathrm{m})$ of Thermo Technologies Corporation, Japan.

Mass spectrometry acquisitions were as follows, Ions polarity: Positive ion model, ion source type: Atmospheric pressure electrospray 


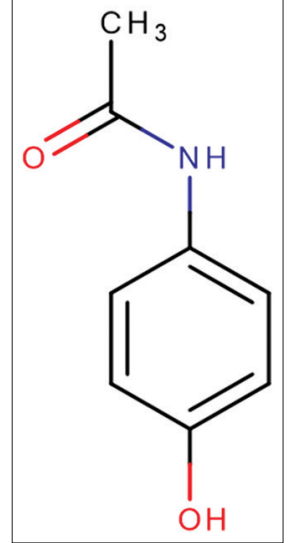

Fig. 1: Chemical structure of paracetamol

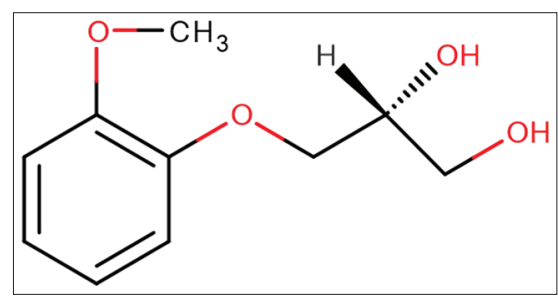

Fig. 2: Chemical structure of guaifenesin

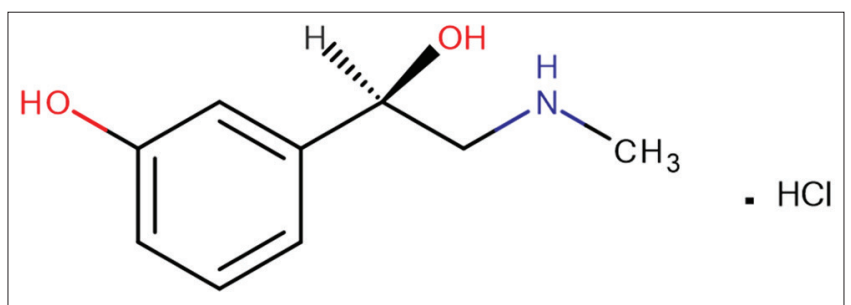

Fig. 3: Chemical structure of phenylephrine hydrochloride

ionization, capillary voltage (kv): 3.00 , con voltage (v), gas temperature: $250\left({ }^{\circ} \mathrm{C}\right)$, gas flow: $11(\mathrm{l} / \mathrm{min})$, nebulizer: 45 (psi), sheath gas heater: $300\left({ }^{\circ} \mathrm{C}\right)$, sheath gas flow: $9(\mathrm{l} / \mathrm{min})$, and nozzle voltage: $500(\mathrm{ev})$.

\section{Preparation of standard solution}

Standard stock solution: An accurately weighed quantity $(10 \mathrm{mg})$ of PCM, GUA, PE, CPM, and AMB were transferred to $10.0 \mathrm{ml}$ volumetric flask, separately. The mixture of methanol:water $(80: 20, \mathrm{v} / \mathrm{v})$ was used as a diluent; all the drugs were dissolved and diluted to the mark to get final concentration $1000 \mathrm{mg} / \mathrm{ml}$. These stock solutions were suitably diluted and used for further study.

\section{Preparation of sample solutions}

Twenty tablets were weighed accurately; average weight was calculated followed by fine powdering. Tablet powder equivalent to $1 \mathrm{mg}$ of CPM was accurately weighed and transferred to a $100 \mathrm{ml}$ volumetric flask. Diluent $(70 \mathrm{ml})$ was added, sonicated for $30 \mathrm{~min}$. Volume was made up to the mark with the diluent. The solution was filtered through Whatman no.1 filter paper, suitably diluted, and used in the study.

\section{Method development}

All drugs were prepared in methanol:water $(80: 20 \mathrm{v} / \mathrm{v})$ as it was found to be a common solvent. A concentration of $10 \mathrm{ng} / \mathrm{ml}$ of all standards was used and injected onto the column for the selection of mobile phase. Water and methanol in different ratios were used in isocratic mode, but the results were found to be non-reproducible. The gradient system was also tried with the same mobile phase. Other chromatographic conditions, especially the composition of the mobile phase, were optimized through several trials

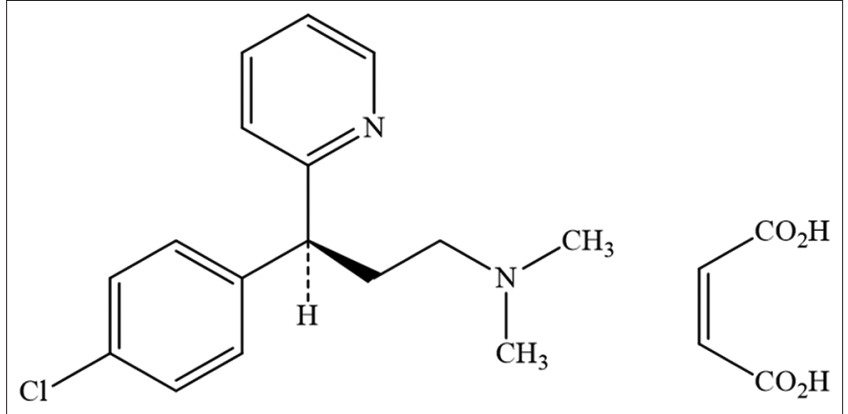

Fig. 4: Chemical structure of chlorpheniramine maleate

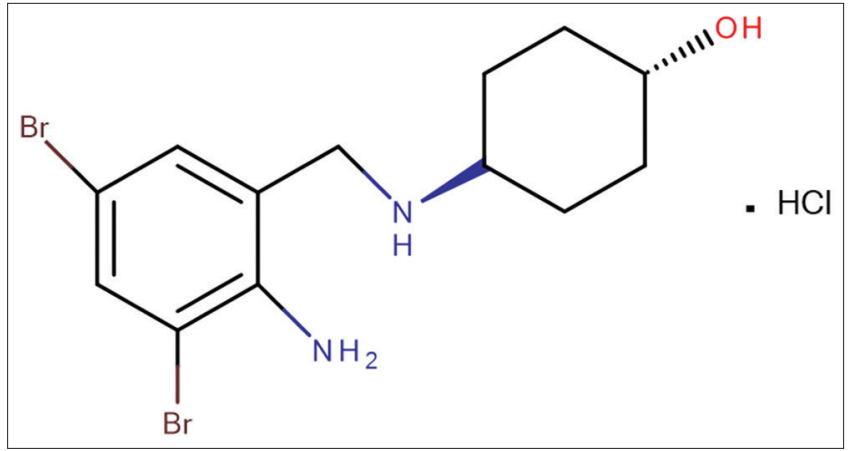

Fig. 5: Chemical structure of ambroxol hydrochloride

to achieve symmetric peak shape, linear response for concentration, and selective multiple reaction monitoring (MRM) transition.

\section{Validation}

Validation of the optimized LC/MS/MS method was carried out as per the International Conference on Harmonization Q2 (R1) guideline [55].

\section{Study of linearity range}

The standard stock solution $(1000 \mathrm{mg} / \mathrm{ml})$ containing PCM, GUA, PE, CPM, and AMB was used to prepare serial dilutions in a range of $10-$ $200 \mathrm{ng} / \mathrm{ml}$ and injected onto the column and chromatographed through optimized chromatographic conditions. This study was repeated 6 times.

\section{Limit of detection (LOD) and limit of quantification (LOQ)}

To estimate the LOD and LOQ, standard deviation (SD) of y-intercept and slopes of calibration curves were used.

\section{Precision}

The precision of the method was confirmed by intra- and inter-day precision. Intraday studies were performed 6 times on the same day at a concentration of $100 \mathrm{ng} / \mathrm{ml}$ for all drugs. The interday precision of the method was checked by repeating analysis at a concentration of $100 \mathrm{ng} / \mathrm{ml}$ for 3 successive days. The percent relative SD (\% RSD) was taken as a measure of precision.

\section{Robustness}

Robustness of the method was checked by making small but deliberates changes in the optimized chromatographic conditions, and the results were examined. The effect of change in flow rate and mobile phase ratio on peak areas was observed. The solution containing $100 \mathrm{ng} / \mathrm{ml}$ of all drug was injected (in triplicate) into sample injector of LC-MS/MS. The retention time and $\%$ RSD of peak areas were calculated for each parameter.

\section{Specificity}

To check the specificity of the LC/MS/MS method, the drugs were studied in MRM. The blank, standard, and sample solutions of PCM, 
GUA, PE, CPM, and AMB were injected in the system, and the RT values for the respective drugs were observed.

\section{Recovery study}

Accuracy was evaluated through percentage recoveries of known amount of mixture of PCM, GUA, PE, CPM, and AMB, added to the solution of formulation. For recovery study, sample stock solution from tablet formulation was prepared. To the above prepared solution, 80, 100, and $120 \%$ of the standard drug solutions were spiked. Dilutions were prepared, and recovery studies were performed. The percentage ratios between the recovered and expected concentrations were estimated in triplicate.

\section{Analysis of marketed formulation}

The drug content of marketed tablet dosage form was determined 6 times using proposed method. Tablet powder equivalent to $1 \mathrm{mg}$ of CPM was accurately weighed and transferred to a $100 \mathrm{ml}$ volumetric flask. Around $70 \mathrm{ml}$ of methanol was added, and the solution was sonicated for $30 \mathrm{~min}$. Volume was made up to the mark with the methanol. The solution was filtered through Whatman no.1 filter

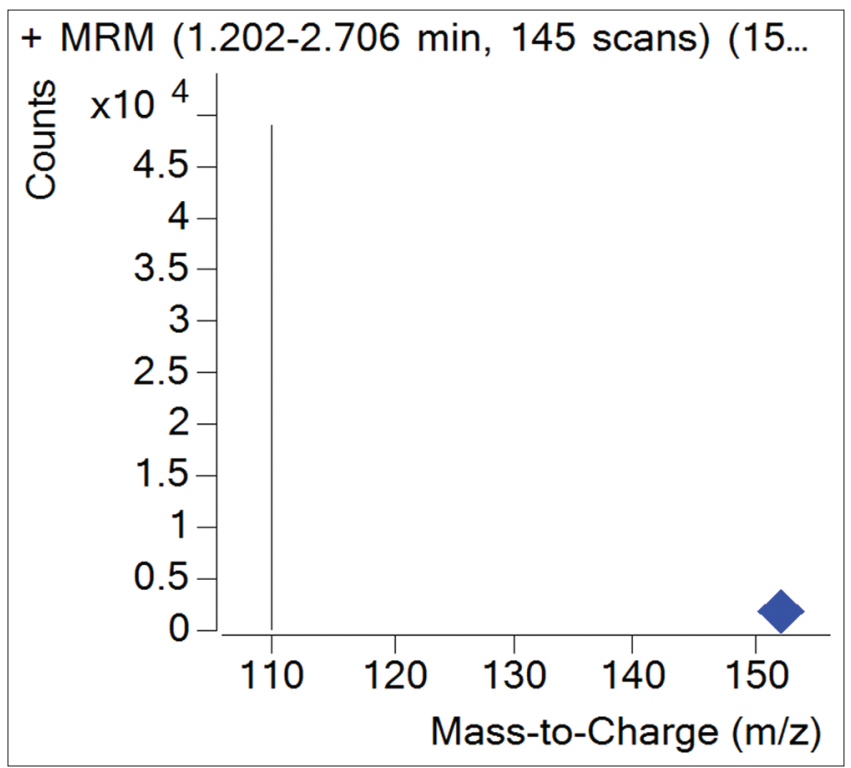

Fig. 6: Parent ion for paracetamol

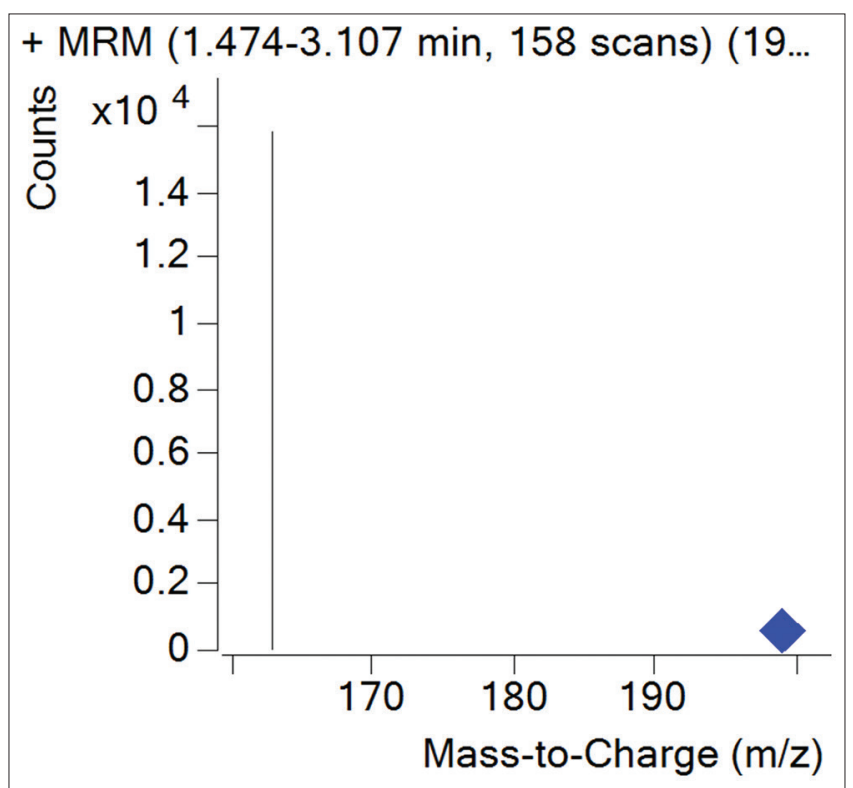

Fig. 7: Parent ion for guaifenesin paper and further diluted to get a concentration of 10,50 , and $150 \mathrm{ng} / \mathrm{ml}$ for CPM, PE, and AMB and 25 and $125 \mathrm{ng} / \mathrm{ml}$ for GUA and PCM used in the study. The percentage content of each drug was determined.

\section{RESULTS AND DISCUSSION}

\section{LC/MS/MS detection}

The parent and product ion were optimized by injecting a $10 \mathrm{ng} / \mathrm{ml}$ standard solution of five drugs in positive polarity mode. The intensity was much higher in the positive mode due to protonation at $\mathrm{m} / \mathrm{z} 152.0$ (PCM), 199.0 (GUA), 168.0 (PE), 275.0 (CPM), and 379.0 (AMB) in Q1MS. Full spectra for drugs are given in Figs. 6-10.

The most abundant product ion at $\mathrm{m} / \mathrm{z} 110.0$ (PCM), 163.0 (GUA), 150.0 (PE), 230.0 (CPM), and 263.8 (AMB) was observed by applying collision energy of $10,5,7,10$, and $15 \mathrm{eV}$, respectively. The MRM parameters were suitably optimized to obtained consistent and adequate response of analytes. Quantitation was performed using MRM mode to study parent to product ion transition for PCM (m/z 152.0 $\geq 110.0)$, GUA $(\mathrm{m} / \mathrm{z} 199.0 \geq 163.0)$, PE (m/z 168.0 $\geq 150.0)$, CPM (m/z 275.0 2230.0$)$, and AMB $(\mathrm{m} / \mathrm{z} 379.0 \geq 263.8)$. Quantitation was done on the basis of major product ions. The product ion spectrum of PCM was due to the fragmentation by loss of neutral ketene $(\mathrm{CH} 2=\mathrm{C}=0)$ molecule. This results in the formation of major product ion at $\mathrm{m} / \mathrm{z}$ 110.0. In GUA, loss of two water molecules results in the formation of major product ion at $\mathrm{m} / \mathrm{z} 163.0$, and in PE, loss of one water molecule results in the formation of major product ion at $\mathrm{m} / \mathrm{z} 150.0$. The product ion spectrum of CPM was due to loss of dimethyl amine ( $\mathrm{CH} 3-\mathrm{NH}-\mathrm{CH} 3)$ to give product ion at $\mathrm{m} / \mathrm{z}$ 230.0. For ambroxol, loss of 4 amino cyclohexanol (C6H13NO) results in the formation of major product ion at $\mathrm{m} / \mathrm{z} 263.8$.

Table 1: Gradient mobile phase

\begin{tabular}{lll}
\hline Time (min.) & Water (\%) & Methanol (\%) \\
\hline 2.00 & 60 & 40 \\
4.00 & 90 & 10 \\
5.00 & 0 & 100 \\
5.01 & 60 & 40 \\
9.00 & 60 & 40 \\
\hline
\end{tabular}

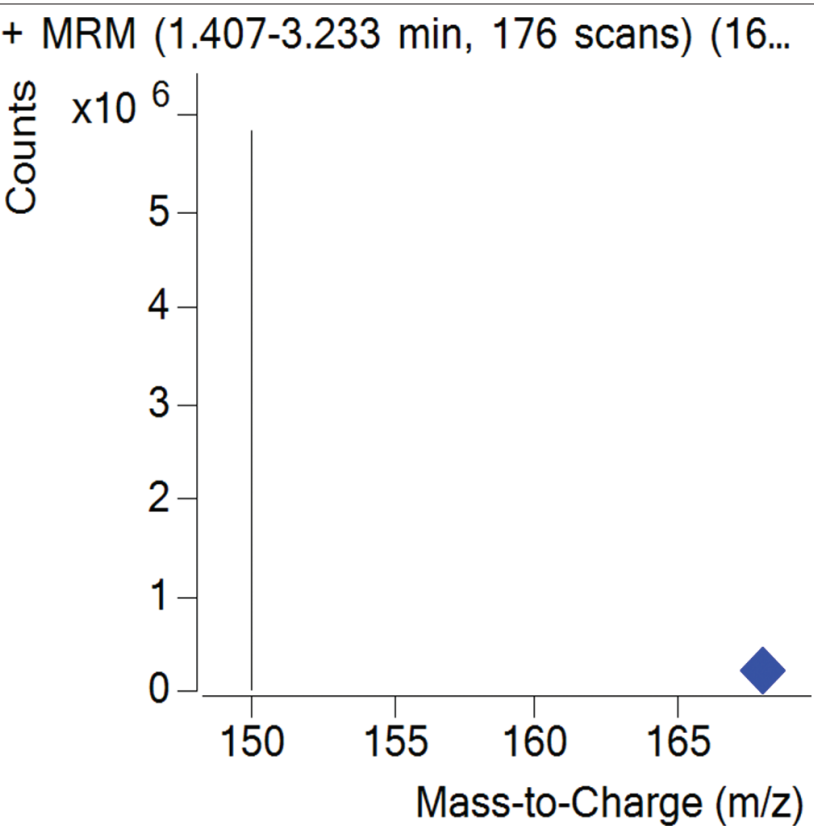

Fig. 8: Parent ion for phenylephrine 
Table 2: Linear regression data for the calibration curves $(n=6)$

\begin{tabular}{|c|c|c|c|c|c|}
\hline Parameters & PCM & GUA & PE & CPM & AMB \\
\hline Linearity range (ng/ml) & $10-200$ & $10-200$ & $10-200$ & $10-200$ & $10-200$ \\
\hline$r^{2}$ & 0.999 & 0.999 & 0.999 & 0.999 & 0.999 \\
\hline Slope & 12196.1 & 44.30 & 110586 & 1305282 & 188087 \\
\hline Intercept & -16493 & 76.82 & 804963.2 & 10520503 & 836191.9 \\
\hline Confidence limit of slope ${ }^{a}$ & 11916.9-12475.3 & $43.3-45.2$ & 108865.3-112307.4 & $8223662-12817344$ & 184822.9-191352.4 \\
\hline Confidence limit of intercept $\mathrm{t}^{\mathrm{a}}$ & $-45297.9-12311.6$ & $-19.1-172.7$ & 627398-982528.4 & $1283021-1327544$ & $499355.6-1173028$ \\
\hline $\mathrm{S}_{\mathrm{y} . \mathrm{x}}^{\mathrm{b}}$ & 11666.3 & 38.85 & 71916 & 930249.8 & 136422.9 \\
\hline
\end{tabular}

a95\% confidence limit, ${ }^{\text {b }} \mathrm{y}_{\mathrm{y} . \mathrm{x}}$ - Standard deviation of residuals from line. PCM: Paracetamol, GUA: Guaifenesin, CPM: Chlorpheniramine maleate, AMB: Ambroxol hydrochloride, PE: Phenylephrine hydrochloride

Table 3: LOD and LOQ of PCM, GUA, PE, CPM, and AMB (n=6)

\begin{tabular}{lll}
\hline Drug & LOD $(\mathbf{n g} / \mathbf{m l})$ & LOQ $(\mathbf{n g} / \mathbf{m l})$ \\
\hline PCM & 3.15 & 9.56 \\
GUA & 2.89 & 8.76 \\
PE & 2.14 & 6.50 \\
CPM & 2.35 & 7.12 \\
AMB & 2.39 & 7.25 \\
\hline
\end{tabular}

PCM: Paracetamol, GUA: Guaifenesin, CPM: Chlorpheniramine maleate, AMB: Ambroxol hydrochloride, LOD: Limit of detection, LOQ: Limit of quantification, PE: Phenylephrine hydrochloride

Table 4: Intra- and inter-day precision of the LC/MS/MS method for PCM, GUA, PE, CPM, and AMB $(n=6)$

\begin{tabular}{llll}
\hline Drug & $\begin{array}{l}\text { Concentration } \\
\mathbf{n g} / \mathbf{m l}\end{array}$ & $\begin{array}{l}\text { Intraday } \\
\text { precision \% RSD }\end{array}$ & $\begin{array}{l}\text { Interday } \\
\text { precision \% RSD }\end{array}$ \\
\hline PCM & 100 & 0.487 & 0.561 \\
GUA & 100 & 0.506 & 0.618 \\
PE & 100 & 0.806 & 0.854 \\
CPM & 100 & 0.337 & 0.434 \\
AMB & 100 & 0.540 & 0.723 \\
\hline
\end{tabular}

PCM: Paracetamol, GUA: Guaifenesin, CPM: Chlorpheniramine maleate, AMB: Ambroxol hydrochloride, \% RSD: Percentage relative Standard deviation, LC/MS/MS: Liquid chromatography tandem-mass spectrometry, PE: Phenylephrine hydrochloride

Method development

The following gradient mobile phase of water:methanol was used for analysis (Table 1 ).

Flow rate was adjusted to $0.3 \mathrm{ml} / \mathrm{min}$. The retention times were found to be $1.76,1.81,1.90,2.10$, and 2.33 min for PCM, GUA, PE, CPM, and $\mathrm{AMB}$, respectively.

\section{Preparation of standard solution}

An accurately weighed quantity (10 mg) of PCM, GUA, PE, CPM, and AMB was transferred separately to $10.0 \mathrm{ml}$ volumetric flasks and dissolved in methanol:water $(80: 20, \mathrm{v} / \mathrm{v})$. Drugs were diluted to the mark to get $1000 \mathrm{mg} / \mathrm{ml}$ concentration for each standard. These stock solutions were further diluted suitably and used in further study. Following are the representative chromatograms of total ion (Fig. 11) and standard drugs (Figs. 12-16) in MRM mode.

\section{Method validation}

Validation of the optimized LC/MS/MS method was carried out with respect to the following parameters:

\section{Linearity range}

To construct the calibration curves by plotting the peak areas versus their corresponding concentrations, the mixed standard drug solutions

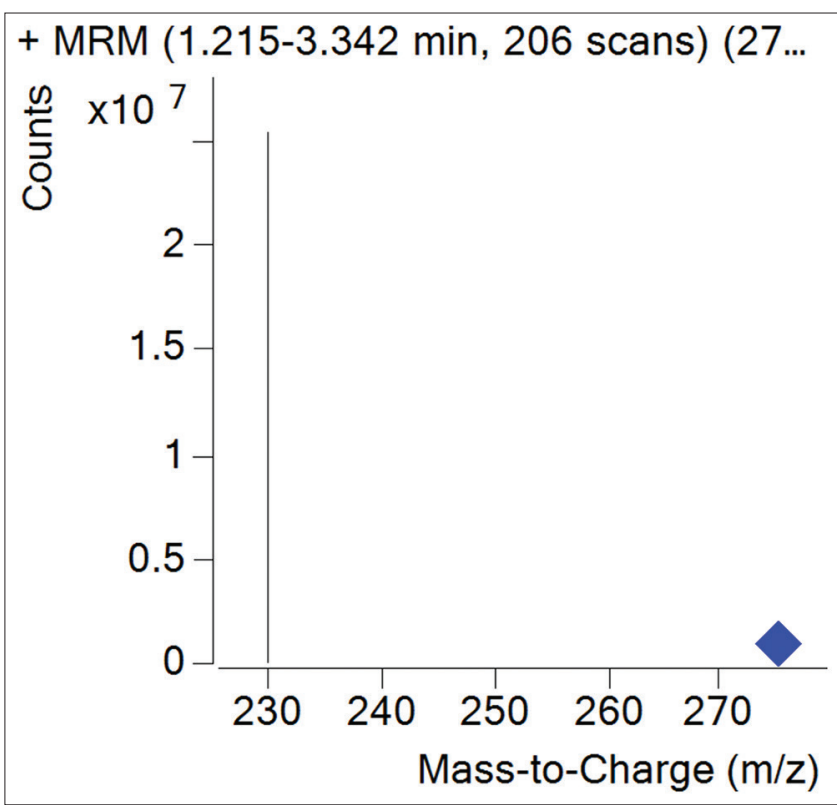

Fig. 9: Parent ion for chlorpheniramine

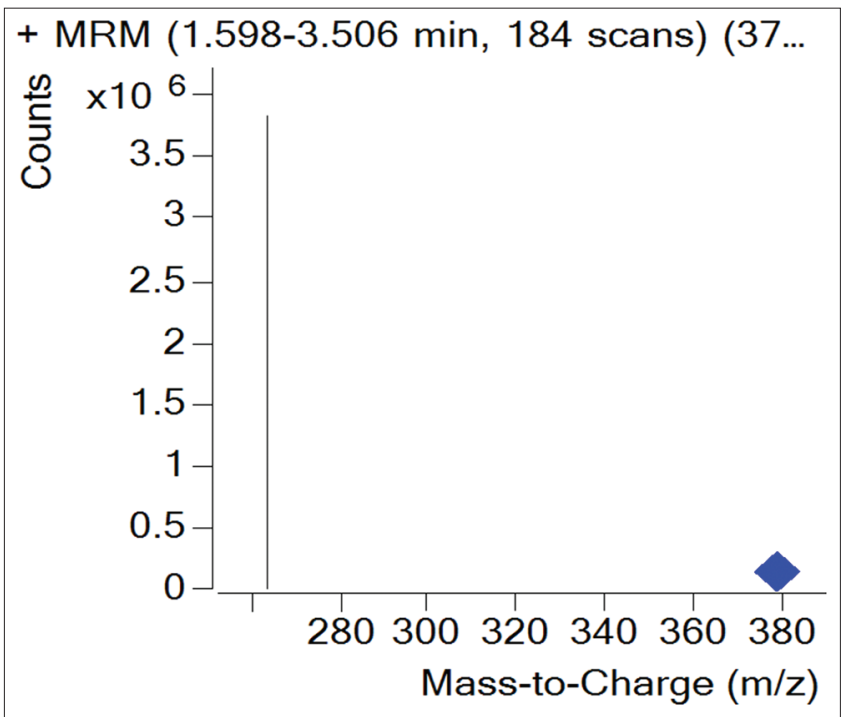

Fig. 10: Parent ion for ambroxol

were injected onto the column in the range of $10-200 \mathrm{ng} / \mathrm{ml}$. The study was repeated 6 times and the mean peak area was considered for the construction of calibration curve. The results were linear over the concentration range of $10-200 \mathrm{ng} / \mathrm{ml}$ for PCM, GUA, PE, CPM, and AMB 
Table 5: Robustness study of PCM, GUA, PE, CPM, and AMB $(\mathrm{n}=3,100 \mathrm{ng} / \mathrm{ml})$

\begin{tabular}{|c|c|c|c|c|}
\hline \multirow{2}{*}{$\begin{array}{l}\text { Parameter varied } \\
\text { Drugs }\end{array}$} & \multicolumn{2}{|c|}{ Mobile phase composition $( \pm 0.1 \mathrm{ml})$} & \multicolumn{2}{|c|}{ Flow rate $(0.3 \pm 0.01 \mathrm{ml} / \mathrm{min})$} \\
\hline & SD of peak area & $\%$ RSD & SD of peak area & $\%$ RSD \\
\hline PCM & 4550.2 & 0.37 & 3952.8 & 0.32 \\
\hline $\mathrm{PE}$ & 91521.8 & 0.78 & 52535.3 & 0.44 \\
\hline CPM & 211848 & 0.15 & 194300.1 & 0.13 \\
\hline AMB & 69433.0 & 0.35 & 46409.8 & 0.23 \\
\hline
\end{tabular}

PCM: Paracetamol, GUA: Guaifenesin, CPM: Chlorpheniramine maleate, AMB: Ambroxol hydrochloride, \% RSD: Percentage relative standard deviation, SD: Standard deviation, PE: Phenylephrine hydrochloride

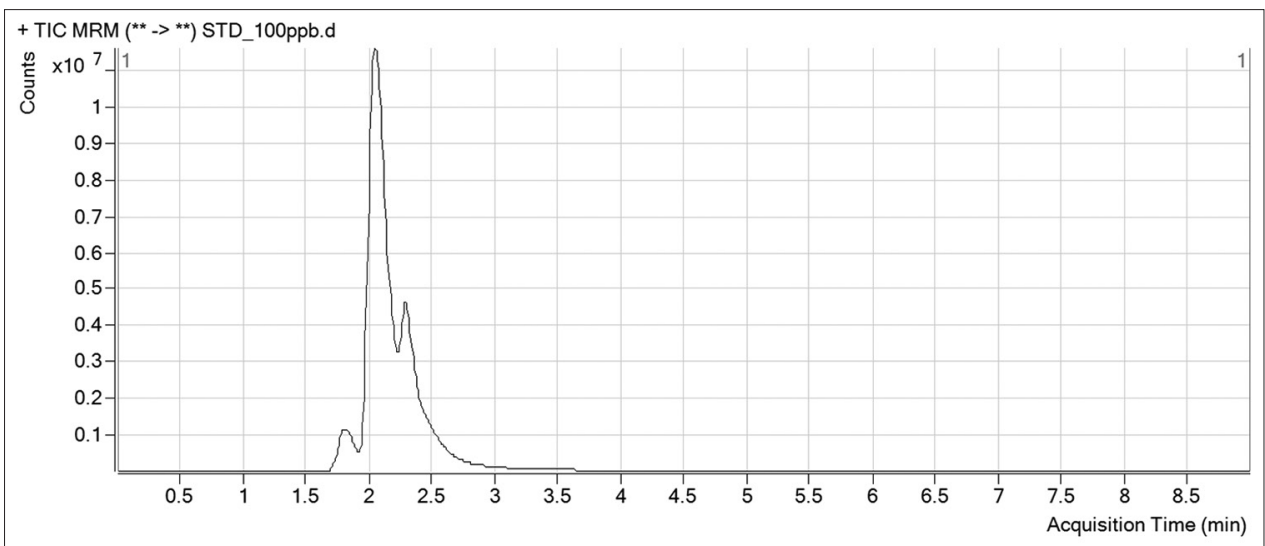

Fig. 11: Representative chromatogram of a mixture of standard drugs

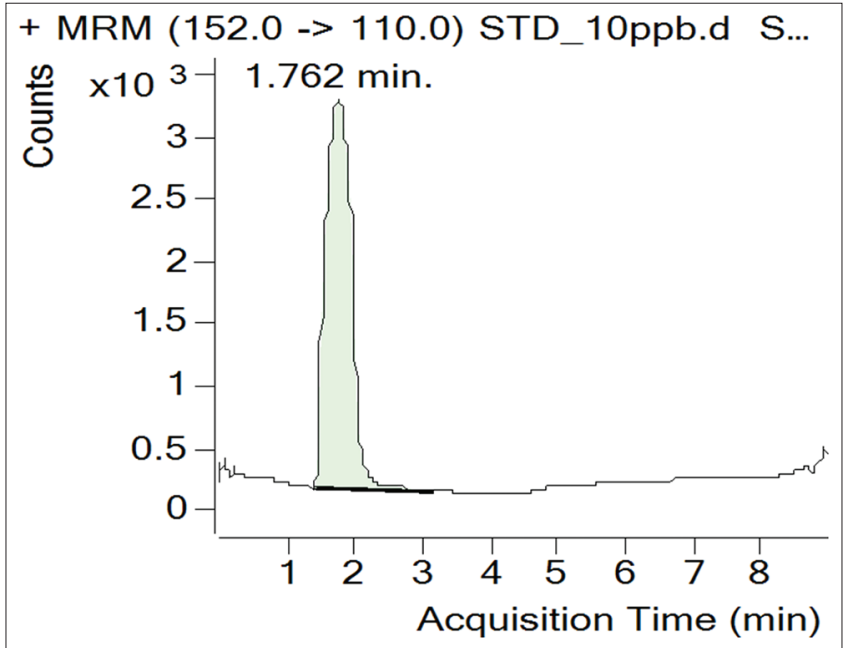

Fig. 12: Representative chromatogram of standard drug paracetamol

(Table 2).

\section{LOD and LOQ}

Based on the SD of response of the calibration curve, LOD and LOQ were determined using formula $3.3 \sigma / \mathrm{S}$ and $10 \sigma / \mathrm{S}$, respectively, where $\sigma$ is the SD of the response (y-intercept) and S is the slope of the linearity plot (Table 3).

\section{Precision}

The developed method was found to be precise, with \% RSD values for repeatability and intermediate precision studies (Table 4) below $2 \%$.

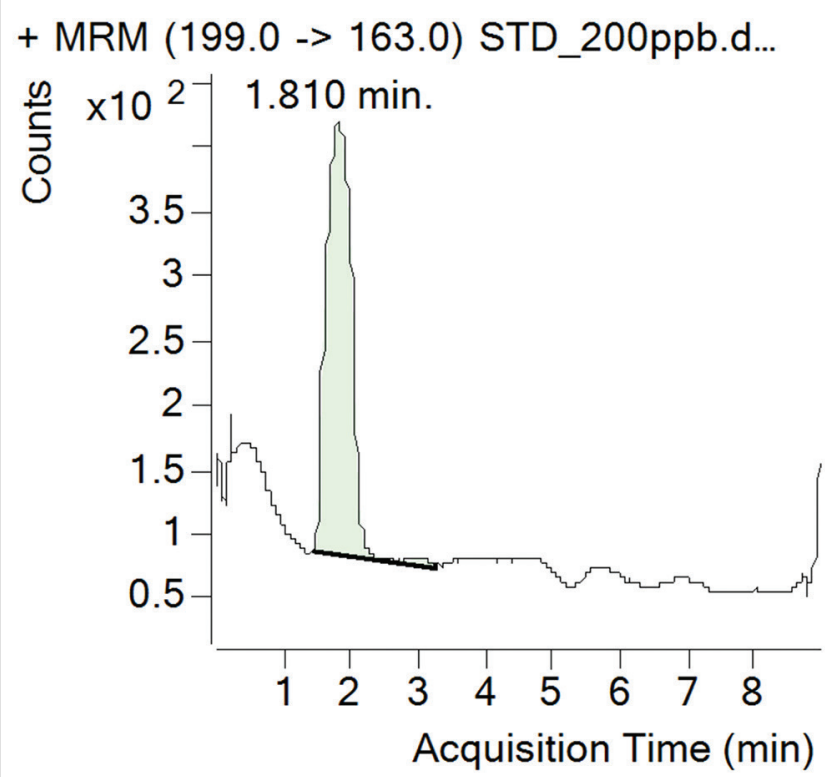

Fig. 13: Representative chromatogram of standard drug guaifenesin

\section{Robustness}

LC/MS/MS method was found to be robust as \% RSD values found to be lower than $2 \%$ (Table 5).

\section{Specificity}

To check the specificity of the LC/MS/MS method, the blank, standard, and sample solutions were injected into the system and the respective retention times were observed. The study showed that there is no interference observed. 
Table 6: Recovery study of PCM, PHE, CPM, GUA, and AMB (n=6)

\begin{tabular}{|c|c|c|c|c|c|c|}
\hline $\begin{array}{l}\text { Original } \\
\text { concentration (mg) }\end{array}$ & $\begin{array}{l}\text { Amount taken } \\
\text { (ng) }\end{array}$ & $\begin{array}{l}\text { Amount added } \\
\text { (ng) }\end{array}$ & $\begin{array}{l}\text { Total amount present } \\
\text { (ng) }\end{array}$ & $\begin{array}{l}\text { Amount Recovered } \\
\text { (ng) }\end{array}$ & \% Recovery & \% RSD \\
\hline \multirow[t]{3}{*}{ PCM 500} & 25 & 20 & 45 & 44.82 & 99.60 & 0.597 \\
\hline & 25 & 25 & 50 & 50.13 & 100.27 & 0.360 \\
\hline & 25 & 30 & 55 & 55.16 & 100.29 & 0.555 \\
\hline \multirow[t]{3}{*}{ GUA 100} & 25 & 20 & 45 & 44.89 & 99.75 & 0.897 \\
\hline & 25 & 25 & 50 & 50.40 & 100.80 & 0.925 \\
\hline & 25 & 30 & 55 & 55.19 & 100.34 & 0.709 \\
\hline \multirow{2}{*}{ AMB 30} & 25 & 25 & 50 & 50.35 & 100.7 & 0.623 \\
\hline & 25 & 30 & 55 & 54.68 & 99.43 & 0.963 \\
\hline \multirow[t]{3}{*}{ PE 10} & 25 & 20 & 45 & 44.98 & 99.96 & 0.966 \\
\hline & 25 & 25 & 50 & 50.25 & 100.50 & 0.934 \\
\hline & 25 & 30 & 55 & 55.06 & 100.12 & 0.950 \\
\hline \multirow[t]{3}{*}{ CPM 2} & 25 & 20 & 45 & 45.30 & 100.67 & 0.980 \\
\hline & 25 & 25 & 50 & 50.01 & 100.02 & 0.705 \\
\hline & 25 & 30 & 55 & 54.75 & 99.55 & 0.722 \\
\hline
\end{tabular}

PCM: Paracetamol, GUA: Guaifenesin, CPM: Chlorpheniramine maleate, AMB: Ambroxol hydrochloride, \% RSD: Percentage relative standard deviation, PE: Phenylephrine hydrochloride

Table 7: Analysis of marketed formulations $(n=6)$

\begin{tabular}{lllll}
\hline Drug & $\begin{array}{l}\text { Label claim } \\
\text { (mg) }\end{array}$ & $\begin{array}{l}\text { Amount found } \\
\text { (mg) }\end{array}$ & $\begin{array}{l}\text { Drug content } \\
\text { (\%) }\end{array}$ & \% RSD \\
\hline PCM & 500 & 500.2 & 100.04 & 0.68 \\
GUA & 100 & 100.2 & 100.20 & 0.44 \\
PE & 10 & 10.009 & 100.09 & 0.56 \\
CPM & 2 & 2.003 & 100.15 & 0.61 \\
AMB & 30 & 29.99 & 99.97 & 0.54 \\
\hline
\end{tabular}

PCM: Paracetamol, GUA: Guaifenesin, CPM: Chlorpheniramine

maleate, AMB: Ambroxol hydrochloride, \% RSD: Percentage relative standard deviation, PE: Phenylephrine hydrochloride

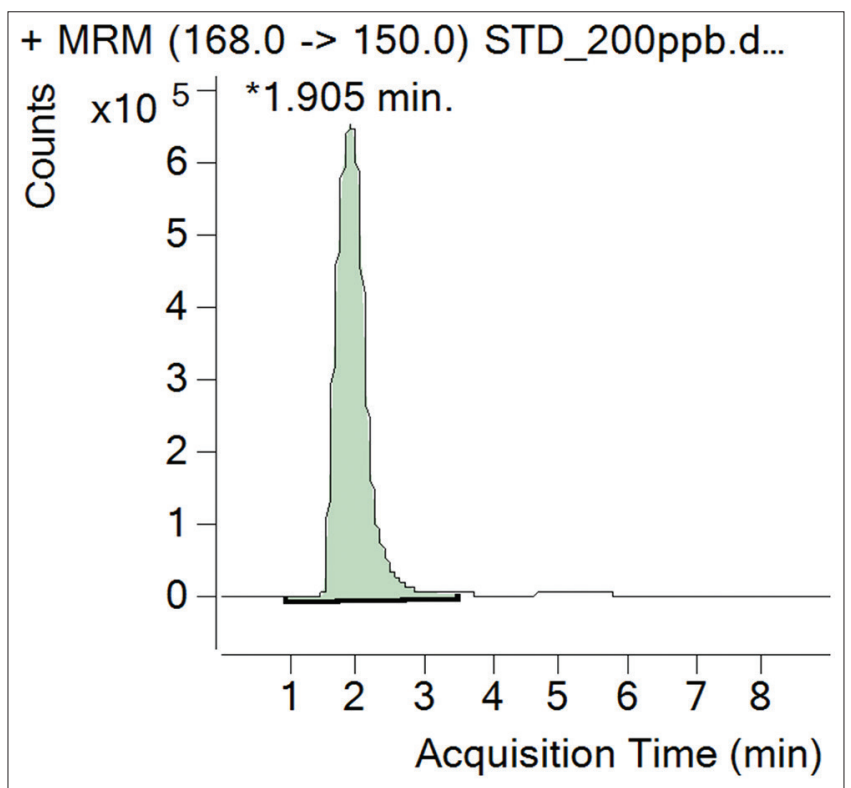

Fig. 14: Representative chromatogram of standard drug phenylephrine

\section{Accuracy}

Developed method found to be accurate as percentage recovery was between 98 and 102\% (Table 6).

Analysis of marketed formulation

Five peaks at m/z 152.0 PCM, 199.0 GUA, 168.0 PE, 275.0 CPM, and 379.0 AMB were observed in the in Q1MS full spectra of the drug

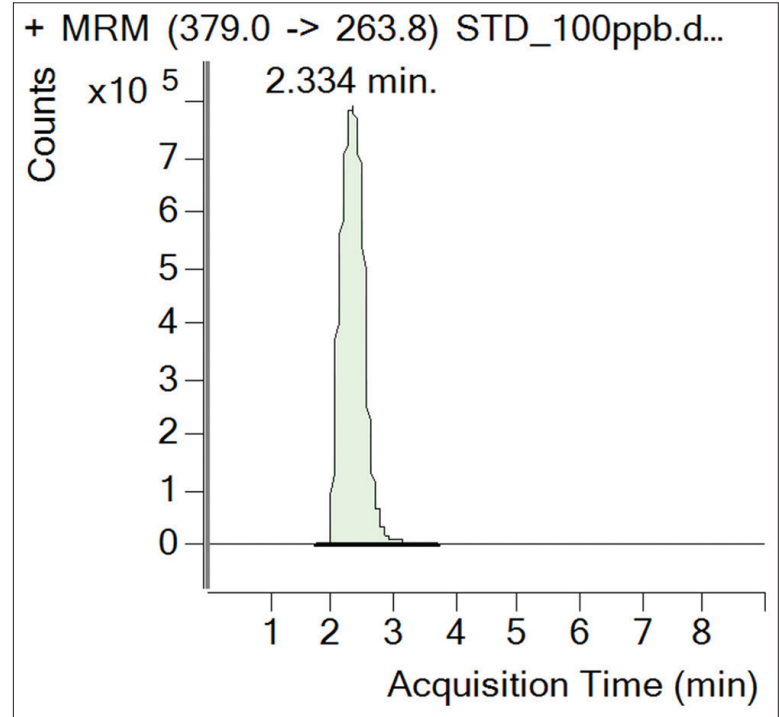

Fig. 16: Representative chromatogram of standard drug ambroxol

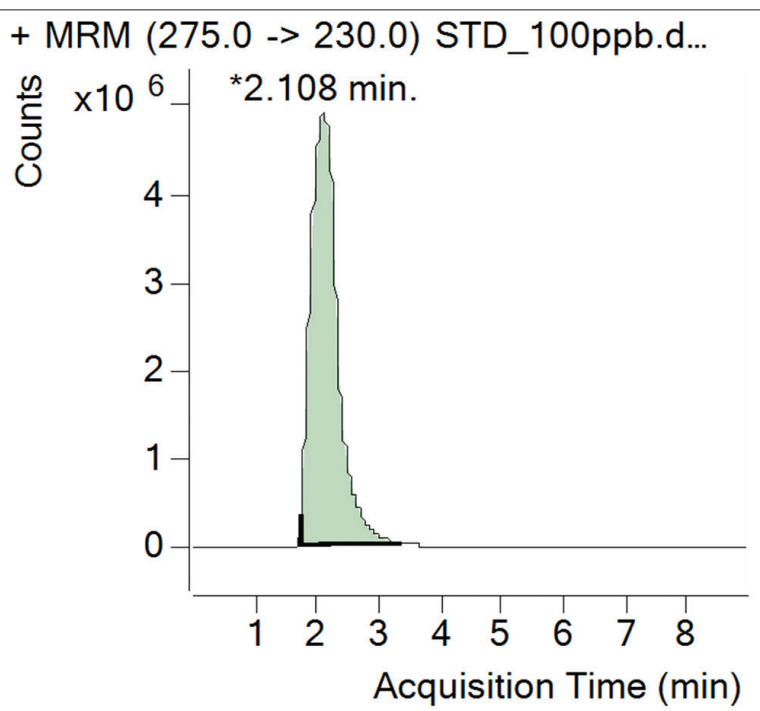

Fig. 15: Representative chromatogram of standard drug chlorpheniramine 
samples extracted from tablet. The content of PCM, GUA, PE, CPM, and AMB was found to be $100.04,100.20,100.09,100.15$, and $99.99 \%$, respectively. The low \% RSD value indicated the suitability of the developed method for routine analysis of PCM, GUA, PHE, CPM, and AMB in pharmaceutical dosage form used in the study by LC/MS/MS technique (Table 7).

\section{CONCLUSION}

In the present research work, an attempt has been made to develop and validate new, precise, accurate, and robust LC/MS/MS method for simultaneous quantification of PCM, guaifenesin, PE, CPM, and AMB in the tablet formulation.

\section{ACKNOWLEDGMENTS}

Authors are also thankful to Principal Dr. (Mrs.) Kiran Bhise, the Management of M.C.E. Society's Allana College of Pharmacy, Pune, India, and Gyan Vihar School of Pharmacy for providing necessary research facilities and Centre for food testing, Poona College of Pharmacy, Erandwane, Pune, Maharashtra, India, for providing technical support and facilities to carry out research work. Authors also express their gratitude to Centaur Pharmaceuticals Limited and Emcure Pharmaceuticals Limited, Pune, Maharashtra, India, for providing gift sample of pure drugs.

\section{AUTHORS' CONTRIBUTION}

All authors have equal contribution in bringing out this article.

\section{CONFLICTS OF INTEREST}

The authors have no conflict of interest.

\section{REFERENCES}

1. Indian Pharmacopoeial Commission. Indian Pharmacopoeia. Vol. 3. New Delhi: Indian Pharmacopoeial Commission, Published by the controller of Publication Gaziabad; 2010. p. 1859.

2. Stationary Office. British Pharmacopoeia. Vol. 1. London: British Pharmacopoeia Commission Secretariat of the Medicines and Healthcare products Regulatory Agency, Stationary Office; 2001. p. 1246.

3. Duong TA, Hoang VD. Simultaneous determination of paracetamol and codeine phosphate in combined tablets by first-order derivative and ratio spectra first-order derivative UV spectrophotometry. Asian J Res Chem 2009;2:143-7.

4. Yadav A, Singh RM, Mathur SC, Saini PK, Gyanendra N. A simple and sensitive HPTLC method for simultaneous analysis of domperidone and paracetamol in tablet dosage forms. J Planar Chromatogr Mod TLC 2009;22:421-4.

5. Deshpande PB, Gandhi SV, Bhangale YS, Pisal VB. High performance thin layer chromatographic method for simultaneous estimation of paracetamol and etoricoxib in combined tablet dosage form. J Pharm Biomed Sci 2010;3:1-5.

6. Kardile SS, Potawale SE, Vidhate SS, Kashid AM, Bansode AS, Choudhury H, et al. Development and validation of HPTLC method for simultaneous estimation of ambroxol hydrochloride, phenylephrine hydrochloride, chlorpheniramine maleate, paracetamol and guaiphenesin in pharmaceutical formulation. J Chem Pharm Res 2015;7:169-77.

7. Godse VP, Deodhar MN, Bhosale AV, Sonawane RA, Sakpal PS, Borkar DD, et al. Reverse phase HPLC method for determination of aceclofenac and paracetamol in tablet dosage form. Asian J Res Chem 2009;2:37-40.

8. Shenoy KR, Krishnamurthy KS, Sumatheendra KS. Determination of codeine phosphate, doxylamine succinate, paracetamol and caffeine in combined dosage formulation by reverse phase liquid chromatography. Indian Drugs Bombay 2000;37:486-8.

9. Adidala RR, Rajamani K, Arrabelli M, Gouru SR. Development and validation of RP-HPLC method for simultaneous estimation of paracetamol, aceclofenac and serratiopeptidase in combined tablet dosage form. World J Pharm Pharm Sci 2015;4:1008-23.

10. Dudhane NP, Umekar MJ, Lohiya RT. A Validated RP-HPLC method for estimation of metoclopramide hydrochloride and paracetamol in solid dosage form. J Pharm Res 2010;3:3064-6.

11. Rekulapally VK, Rao VU. A novel stability RP-HPLC method development and validation for simultaneous estimation of phenylephrine, acetaminophen, guaifenesin and dextromethorphan in tablet dosage form. Der Pharm Lett 2015;7:329-39.

12. Indian Pharmacopoeial Commission, Published by the controller of publication Gaziabad. Indian Pharmacopoeia. Vol. 2. New Delhi: Indian Pharmacopoeial Commission, Published by the controller of publication Gaziabad; 2010. p. 1429-31.

13. Stationary Office. British Pharmacopoeia. London: British Pharmacopoeia Commission Secretariat of the Medicines and Healthcare products Regulatory Agency, Stationary Office; 2001. p. 823 .

14. Bhattacharya I, Bhattacharyya SP, Kyal C, Choudhury P, Dhakal B, Ghosh SK. Estimation and validation of stability indicating UV spectrophotometric method for the determination of guaifenesin in presence of its degradant products. Int J Pharm Pharm Sci 2013;5:262-8.

15. Bankar AA, Lokhande SR, Sawant RL, Bhagat AR. Spectrophotometric estimation of guaifenesin and salbutamol in pure and tablet dosage form by using different methods. Der Pharm Chem 2013;5:92-7.

16. Pushpalatha E, Tejaswini P, Najboonbi M, Vineesha S, Madhanna MD, Anil KT, et al. Development of UV Spectroscopic method for the determination of Guaifenesin in bulk and formulation. Int J Pharm Res Anal 2015;5:90-5.

17. Koteswara RB, Jyothsna KI, Nageswara M, Ram BC. A new and sensitive UV Spectrophotometric method for the determination of Guaifenesin in dosage forms. Int J Pharm Pharm Res 2015;3:140-8.

18. Sagathiya K, Bagada H. Development and validation of RP-HPLC and HPTLC method of analysis for simultaneous estimation of ambroxol $\mathrm{HCl}$, dextromethorphan $\mathrm{HBr}$ and guaifenesin in pharmaceutical cough cold preparation and statistical comparison of developed methods. Int J Pharm Pharm Sci 2014;6:312-6.

19. Abdelkawy M, Metwaly F, Raghy NE, Hegazy M, Fayek N. Simultaneous determination of Ambroxol Hydrochloride and Guaifenesin by HPLC, TLC, Spectrodensitometric and multivariate calibration methods in pure form and in Cough Cold Formulations. J Chromatogr Separat Tech 2011;2:2-9.

20. Senthilraja M, Giriraj P. Reverse phase HPLC method for the simultaneous estimation of terbutanile sulphate, bromhexine $\mathrm{HCl}$ and guaifenesin in cough syrup. Asian J Pharm Clin Res 2011;4:13-5.

21. Walode SG, Deshpande SD, Deshpande AV. Stability indicating RPHPLC method for simultaneous estimation of salbutamol sulphate and guaifenesin. Der Pharm Sin 2013;4:61-7.

22. Suma CH, Vasantha K, Reddy AP, Kumar CA, Nalluri BN. Simultaneous estimation of phenylephrine hydrochloride and guaifenesin inbulk drug and pharmaceutical dosage forms by RP-HPLC-PDA method. J Chem Pharm Res 2013;5:188-94.

23. Hajare PP, Laware RB, Bhusal RD, Magar MM. A validated RP-HPLC method for estimation of Guaifenesin in bulk dosage form. Indo Am J Pharm Sci 2016;3:44-51

24. Yolanda M, Martono S, Rohman A. Validation of an ion-pair high performance liquid chromatography for the determination of pseudoephedrine $\mathrm{HCl}$, guaifenesin and dexchlorpheniramine maleate in cough and cold medicines. Int J Pharm Clin Res 2016;8:476-80.

25. Indian Pharmacopoeial Commission, Published by the controller of publication Gaziabad. Indian Pharmacopoeia. Vol. 3. New Delhi: Indian Pharmacopoeial Commission, Published by the controller of Publication Gaziabad; 2010. p. 1899-900.

26. Stationary Office. British Pharmacopoeia. Vol. 1. London: British Pharmacopoeia Commission Secretariat of the Medicines and Healthcare products Regulatory Agency, Stationary Office; 2001. p. 1294.

27. Wagh RS, Hajare RA, Tated A, Chandewar AV. Absorption correction method and simultaneous equation method for the simultaneous estimation of ebastine and phenylephrine hydrochloride in bulk and in combined tablet dosage form. Int J Res Pharm Chem 2011;1:812-9.

28. Janwitayanuchit W, Lukkanatinaporn P. Development of HPTLC method for determination of brompheniramine maleate and phenylephrine hydrochloride tablets. Int J Pharm Pharm Sci 2014;6:106-9.

29. Parmar K, Bhavsar A, Patel B. Method development and validation for simultaneous estimation of ebastine and phenylephrine in bulk and solid oral dosage form by HPLC. World J Pharm Pharmaceut Sci 2014;3:1312-20

30. Patel AH, Solanki SD. Analytical method development and validation for simultaneous determination of ebastine and phenylephrine hydrochloride in combined pharmaceutical dosage form. Int J Pharma Res Biosci 2014;3:279-94. 
31. Sheikh S, Asghar S, Ahmad S. RPHPLC method for simultaneous estimation of phenylepherine $\mathrm{HCl}$, guaifenesin, bromhexine $\mathrm{HCl}$, Cetirizine $\mathrm{HCl}$ inpharmaceutical liquid formulation. Int J Pharm Res Sch 2013;2:448-57.

32. Deo SS, Inam F, Deshmukh TB, Lambat TL. Development and validation of RP-HPLC method for simultaneous determination of phenylepherine hydrochloride and cetirizine hydrochloride in tablet dosage form. Int J Pharm Sci Res 2015;6:4069-74.

33. Sheikh S, Asghar S, Patni SA. A validated, specific stability indicating reverse phase liquid chromatographic method for the simultaneous estimation of phenylephrine $\mathrm{HCl}$, betamethasone valerate and lignocaine $\mathrm{HCl}$ in pharmaceutical ointment. Int J Sci Res 2012;2:1-8.

34. Indian Pharmacopoeial Commission, Published by the controller of publication Gaziabad. Indian Pharmacopoeia. Vol. 2. New Delhi: Indian Pharmacopoeial Commission, Published by the Controller of Publication Gaziabad; 2010. p. 1070.

35. Stationary Office. British Pharmacopoeia. Vol. 1. London: British Pharmacopoeia Commission Secretariat of the Medicines and Healthcare products Regulatory Agency, Stationary Office; 2001. p. $394-5$.

36. Reddy GS, Bhaskar D, Kamarapu SK. Method development and validation of UV spectroscopic method for simultaneous estimation of chlorpheniramine maleate and diethylcarbamazine citrate in combined tablet dosage forms. Int J Pharm Biol Sci 2013;3:216-23.

37. Wadher SJ, Kalyankar TM, Panchal PP. Development and validation of simultaneous estimation of chlorpheniramine maleate and phenylephrine hydrochloride in bulk and capsule dosage form by ultraviolet spectrophotometry. Int J Chem Tech Res 2013;5:2410-9.

38. Hanan NA, Mutaz SS. Simultaneous quantitative determination of codeine phosphate, chlorpheniramine maleate phenylephrine hydrochloride and acetaminophen in pharmaceutical dosage forms using thin layer chromatography densitometry. Anal Lett 1986;19:915-24.

39. Nalini K, Narmada P, Lakshmi GV, Gowtham Y, Jogi KV. Simultaneous estimation of paracetamol, guaiphensin, phenylephrine $\mathrm{HCl}$, chlorpheniramine maleate and bromohexine $\mathrm{HCl}$ in combined tablet dosage form by reverse phase high performance liquid chromatography. Int J Pharm Sci Res 2014;5:410-6.

40. Redasani VK, Gorle AP, Badhan RA, Jain PS, Surana SJ. Simultaneous determination of chlorpheniramine maleate, phenylephrine hydrochloride, paracetamol and caffeine in pharmaceutical preparation by RP-HPLC. Chem Ind Chem Eng Quarterl CICEQ 2013;19:57-65.

41. Ladmeera, Raj H, Jain V. Development and validation of analytical method for bromhexine $\mathrm{HCl}$, chlorpheniramine maleate and guaifenesin by simultaneous equation method. Asian J Pharma Sci 2015;5:76-82.

42. Jain V, Mukesh CS. Validated RPHPLC method for determining the levels of bromhexine $\mathrm{HCl}$, chlorpheniramine maleate, dextromethorphan Hbr and guaiphenesin in their pharmaceutical dosage forms. J Taibah Uni Sci 2016;10:38-45.

43. Abdulbari MM, Ihsan MS. Simultaneous determination and validation of chlorpheniramine maleate, acetaminophen, phenylpropanolamine hydrochloride and caffeine in tablet dosage form by using reverse phase high performance liquid chromatography (RP-HPLC). Int J Pharm Pharm Sci 2013;5:666-70

44. Rajurkar S. Simultaneous determination of chlorpheniramine maleate, paracetamol and pseudo ephedrine hydrochloride in pharmaceutical preparations by HPLC. Int J Life Sci Pharma Res 2011;1:94-100.

45. Indian Pharmacopoeial Commission, Published by the controller of publication Gaziabad. Indian Pharmacopoeia. Vol. 2. New Delhi: Indian Pharmacopoeial Commission, Published by the controller of publication Gaziabad; 2010. p. 792

46. Akhtar J, Padaria M. Development and validation of UV spectrophotometric methods for simultaneous determination of doxofylline and ambroxol hydrochloride in bulk and their combined dosage form. Indo Glob J Pharm Sci 2013;3:90-5.

47. Patil JS, Rane CR, Ingale RD. Simultaneous spectrophotometric methods for estimation of levocetirizine and ambroxol in pharmaceutical dosage form. J Chem Biophy Sci Sec 2013;3:1115-22.

48. Mulla S, Patil A, Morge S, Kulkarni S. Development and validation of HPTLC method for the simultaneous estimation of roxithromycin and ambroxol hydrochloride in combined dosage form. IOSR J Pharm 2012;2:4-7.

49. Dhaneshwar SR, Dhoka MV, Chopade SS, Bhusari VK. Validated HPTLC method for simultaneous estimation of amoxycillin trihydrate and ambroxol hydrochloride in pharmaceutical dosage form. Asian $\mathrm{J}$ Pharm Biol Res 2011;1:129-35

50. Tompe PU, Shinde NV, Damle MC, Madgulkar AR. Development and validation of bioanalytical method for the determination of ambroxol hydrochloride and cefadroxil in human plasma. Int J Pharm Biomed Res 2013;4:1239-48.

51. Gugulothu S, Bollikolla H. A validated high performance liquid chromatography method for the simultaneous analysis of guaifenesin, ambroxol and loratidine in bulk and liquid dosage form. J Appl Pharm Sci 2015;5:61-6.

52. Rao AS, Kumar KL, Satyanarayana P, Sastry GS. A validated RP-HPLC method for the simultaneous estimation of guaifenesin, ambroxol, and levo cetirizine in pharmaceutical dosage forms. World J Pharma Pharm Sci 2015; 4:1735-47

53. Ghosh A, Mandal SK, Ghosh S, Deb S. Development and validation of RP-HPLC method for simultaneous determination of terbutaline sulphate, guaiphenesin and ambroxol hydrochloride from an oral liquid. Indian Drugs 2016;53:53-6.

54. Gopalakrishnan S, Chitra TA, Aruna A, Chenthilnathan A. Development of RP-HPLC method for the simultaneous estimation of ambroxol hydrochloride, cetirizine hydrochloride and antimicrobial preservatives in combined dosage form. Der Pharm Chem 2012;4:1003-15.

55. International Conference on Harmonization. ICH Harmonized Tripartite Guideline Validation of Analytical Procedures: Text and Methodology Q2 (R1) ICH. Geneva: International Conference on Harmonization 2005. 